\title{
Superficial and Juxtamedullary Nephron Function during Saline Loading in the Dog
}

\author{
Frank J. Bruns, Edward A. Alexander, Arthur L. Ruley, and \\ NORMAN G. LEVINSKY \\ From the Departments of Medicine, Boston University School of Medicine, \\ Boston City Hospital, and University Hospital, Boston University Medical \\ Center, Boston, Massachusetts 02118
}

\begin{abstract}
A B S T R A C T A modification of the microdissection technique of Hanssen was utilized in dogs to measure superficial (SNGFR) and juxtamedullary nephron filtration rate (JMGFR) in control and saline-expanded dogs. During control studies SNGFR was $60 \pm 4$ and JMGFR was $72 \pm 5 \mathrm{nl} / \mathrm{min}$. During saline loading SNGFR was $74 \pm 8$ and JMGFR was $65 \pm 6 \mathrm{nl} / \mathrm{min}$. The ratio SNGFR: JMGFR significantly increased from $0.84 \pm 0.03$ to $1.15 \pm 0.08$. Glomerular perfusion rate (GPR) was measured with the microsphere method during control and saline loading. Superficial GPR did not change significantly but juxtamedullary GPR increased from $225 \pm 42$ to $323 \pm 39 \mathrm{nl} / \mathrm{min}$. Calculated superficial nephron filtration fraction was unchanged after saline expansion but juxtamedullary filtration fraction decreased from $0.34 \pm 0.07$ to $0.24 \pm 0.07$. The data demonstrate a tendency for filtration to shift toward the superficial part and plasma flow toward the deep part of the kidney cortex. GFR in juxtamedullary nephrons appears to be less plasma flow-dependent than in superficial nephrons. The fall in filtration fraction in the deep cortex may affect sodium excretion by juxtamedullary nephrons.
\end{abstract}

\section{INTRODUCTION}

Distribution of blood flow and glomerular filtration $(G F R)^{1}$ within the kidney during volume expansion

This work was presented in part before the American Federation of Clinical Research, Atlantic City, April 30, 1972.

Dr. Bruns' present address is Montefiore Hospital, Pittsburgh, $\mathrm{Pa}$.

Dr. Riley's present address is Veterans Administration Hospital, Wood, Wis.

Received for publication 16 July 1973 and in revised form 14 December 1973.

${ }^{1}$ Abbreviations used in this paper: $\mathrm{C}_{\mathrm{IN}}, \mathrm{C}_{\mathrm{PAB}}$, clearance have been under active investigation because they may be important determinants of sodium excretion. While a number of methods have been used to determine intrarenal distribution of blood flow in the dog, no quantitative estimates of both juxtamedullary and superficial nephron filtration rates (JMGFR and SNGFR) have been made in this species. A number of investigators have attempted to determine changes in distribution of GFR among nephrons from comparison of changes in the ratio of SNGFR, obtained by micropuncture, to whole kidney GFR. Since juxtamedullary nephrons are a small proportion (5-15\%) of the total number, it is obvious that substantial changes in GFR of juxtamedullary nephrons could be missed by this indirect technique. Using this method, most investigators have found no evidence for redistribution of filtrate during saline loading in dogs (1-3). Recently Carriere, Boulet, Mathieu, and Brunette (4) have applied the Hanssen method to dogs to obtain direct measurements of the ratio of SNGFR to JMGFR. They found that this ratio did not change after saline infusion. At the same time (5), we had adapted a modification (6-8) of the Hanssen method $(9,10)$ to permit quantitative estimates of both superficial and deep nephrons separately. In addition, we have determined the distribution of blood flow within the cortex with microspheres in the same animals. The combination of these methods has allowed us to re-examine the effect of saline expansion on superficial and deep nephron filtration and perfusion rates and to estimate superficial and deep nephron filtration fraction before and during saline expansion. Our results indicate that SNGFR increases proportionately more than JMGFR after saline expan-

of inulin and PAH; GFR, glomerular filtration rate; GPR, glomerular perfusion rate; JMGFR, juxtamedullary glomerular filtration rate; PAH, $p$-aminohippurate; SNGFR, superficial nephron filtration rate. 
TABLE I

Control Animals, Group I

\begin{tabular}{|c|c|c|c|c|c|c|c|c|c|c|}
\hline \multirow[b]{2}{*}{ Exp. } & \multirow[b]{2}{*}{ Dog wt } & \multirow[b]{2}{*}{$\mathrm{C}_{\mathrm{IN}}$} & \multicolumn{2}{|c|}{ Nephron GFR } & \multirow{2}{*}{$\frac{\text { Sup }}{J M}$} & \multirow[b]{2}{*}{$\mathrm{C}_{\mathrm{PAH}}$} & \multicolumn{2}{|c|}{ Zonal plasma flow } & \multicolumn{2}{|c|}{ GPR } \\
\hline & & & Sup & $\mathrm{JM}$ & & & Sup & $\mathrm{JM}$ & Sup & $\mathrm{J} \mathbf{M}$ \\
\hline & $k g$ & $m l / m i n$ & \multicolumn{2}{|c|}{$n l / \min$} & & $m l / m i n$ & \multicolumn{2}{|c|}{$\mathrm{ml} / \mathrm{min} / \mathrm{g}$} & \multicolumn{2}{|c|}{$n l / \min$} \\
\hline 1 & 13 & 31 & $77 \pm 4.3$ & $89 \pm 9.7$ & 0.87 & & & & & \\
\hline 2 & 22 & 18 & $58 \pm 4.4$ & $69 \pm 4.9$ & 0.84 & & & & & \\
\hline 3 & 11.5 & 32 & $56 \pm 3.6$ & $80 \pm 7.3$ & 0.70 & & & & & \\
\hline 4 & 14 & 37 & $66 \pm 5.6$ & $74 \pm 9.2$ & 0.90 & & & & & \\
\hline 5 & 11.5 & 32 & $46 \pm 3.1$ & $42 \pm 2.4$ & 1.08 & & & & & \\
\hline 6 & 14.5 & 40 & $77 \pm 3.8$ & $90 \pm 2.5$ & 0.86 & 105 & 2.34 & 1.01 & 222 & 179 \\
\hline 7 & 11.5 & 24 & $50 \pm 1.7$ & $57 \pm 4.0$ & 0.88 & & & & & \\
\hline 8 & 11.5 & 20 & $76 \pm 2.9$ & $92 \pm 3.8$ & 0.82 & 42 & 1.97 & 1.08 & 187 & 191 \\
\hline 9 & 12.8 & 22 & & & & 38 & 1.32 & 0.97 & 125 & 172 \\
\hline 10 & 14.0 & 33 & $62 \pm 2.9$ & $73 \pm 3.0$ & 0.85 & 80 & 2.24 & 1.70 & 212 & 301 \\
\hline 11 & 16.0 & 39 & $50 \pm 3.1$ & $62 \pm 2.3$ & 0.81 & 100 & 1.42 & 0.94 & 135 & 166 \\
\hline 12 & 11.2 & 26 & $41 \pm 2.8$ & $61 \pm 2.5$ & 0.67 & 146 & 2.92 & 2.92 & 277 & 517 \\
\hline Mean & 13.6 & 29 & 60 & 72 & 0.84 & 85.0 & 2.04 & 1.44 & 193 & 254 \\
\hline$\pm \mathrm{SEM}$ & 0.9 & 2.2 & 3.9 & 4.7 & 0.03 & 16.8 & 0.23 & 0.32 & 23 & 56 \\
\hline
\end{tabular}

Values are means \pm SE. Abbreviations: Sup, superficial; JM, juxtamedullary.

sion. Moreover, filtration fraction in juxtamedullary nephrons appears to fall strikingly after saline loading. It is possible that significant differences in sodium excretion from superficial and deep nephrons during saline loading may result from these heterogeneous hemodynamic shifts within the kidney. Moreover, the striking change in filtration fraction in juxtamedullary nephrons suggests that GFR in this class of nephrons is not as flow-dependent as in superficial nephrons.

\section{METHODS}

Studies were performed on mongrel dogs weighing between 9.5 and $22 \mathrm{~kg}$. Food and water were withheld $4-6 \mathrm{~h}$ before study. All dogs were anesthetized with pentobarbital and intubated. For microsphere injection, a 2-mm-ID polyvinyl catheter was advanced through the right axillary artery into the aortic root or the left ventricle. Polyethylene catheters were inserted into leg veins for infusions of inulin, $p$-aminohippurate (PAH), and $0.87 \%$ saline when appropriate. Two catheters were advanced from the femoral artery to an intra-aortic position just above the renal arteries, a PE50 catheter for infusion of radiolabeled $\mathrm{FeCN}$, and a PE160 catheter to monitor blood pressure, sample blood, and infuse unlabeled $\mathrm{FeCN}$.

Through bilateral flank incisions, both ureters were catheterized near the renal pelvis. The right kidney was exposed and the renal artery was isolated. To measure the activity of $\left[{ }^{14} \mathrm{C}\right]$ sodium ferrocyanide $(\mathrm{FeCN})$ in the renal artery blood, a 23-gauge hooked needle was placed in the right renal artery and kept open with a heparinized saline infusion at a rate of $0.3 \mathrm{ml} / \mathrm{min}$. Finally, a heavy cord ligature was placed loosely around the renal pedicle.

${ }^{85} \mathrm{Sr}$ or ${ }^{141} \mathrm{Ce}$-labeled microspheres (15 $\mu \mathrm{m}, 3 \mathrm{M}$ Co., St. Paul, Minn.), suspended in $10 \%$ dextran, were used to measure regional blood flow. After suspension with an ultrasonic probe, $5-10 \times 10^{5}$ spheres of each isotope, containing about $10 \mu \mathrm{Ci}$ were rapidly injected and the catheter was flushed with $10 \mathrm{ml}$ of saline.

Nephron GFR was determined at the end of each experiment with a modification of Hanssen's technique (6-8). $2.2 \mathrm{ml} 20 \% \mathrm{FeCN}$ was mixed with $900-1,200 \mu \mathrm{Ci} \cdot\left[{ }^{14} \mathrm{C}\right]-$ $\mathrm{FeCN}^{2}$ (New England Nuclear, Boston, Mass.) and infused through the aortic catheter over a carefully timed interval of $14-16 \mathrm{~s}$, at $8.0 \mathrm{ml} / \mathrm{min}$. Simultaneous with the onset of the ${ }^{14} \mathrm{C}$ infusion, a $4.0 \mathrm{ml}$ bolus of $20 \% \mathrm{FeCN}$ was injected over $1-2 \mathrm{~s}$ to mark by a visible precipitate in tubules the start of the timed isotope infusion (see below). Blood for determination of ${ }^{14} \mathrm{C}$-labeled $\mathrm{FeCN}$ was collected from the renal artery needle continuously in 1-s aliquots during the entire 14-16-s infusion in every experiment. At the end of the infusion the renal pedicle was rapidly lighted, cut, and the kidney transferred within 15 $s$ to an isopentane bath precooled in an acetone-dry ice slush to $-75^{\circ} \mathrm{C}$. After the kidney had then been frozen for $2 \mathrm{~min}$, excess fat and the renal pelvis were trimmed and the kidney was weighed.

The dogs were divided into two groups. Group I: in 12 dogs, after clearance periods for inulin and $\mathrm{PAH}$, either ${ }^{87} \mathrm{Sr}$ or ${ }^{141} \mathrm{Ce}$-labeled microspheres were given through the left ventricular catheter and the Hanssen procedure was performed. Group II : in $12 \mathrm{dogs}$, after control measurements and microsphere injection as above, $0.87 \%$ saline to equal $10 \%$ body wt was infused over $1 \mathrm{~h}$, then continued at a rate equal to $5 \%$ body $\mathrm{wt} / \mathrm{h}$. $60-75 \mathrm{~min}$ after starting the saline, infusion, clearance periods were begun. Midway through these collections differently radiolabeled microspheres were injected and at the end of the clearance periods the Hanssen procedure was performed. Because of technical difficulties, data for both nephron GFR and

${ }^{2}$ Purity of each lot of radiolabeled ferrocyanide was checked by chromatography. In addition, the clearance of most lots of radioactive ferrocyanide was compared to that of inulin in rats or dogs. The clearances, as others have also reported (11), were not different. 
TABLE II

The Effect of Saline Loading, Group II

\begin{tabular}{|c|c|c|c|c|c|c|c|c|c|c|c|c|c|c|c|c|}
\hline \multirow[b]{3}{*}{ Exp } & \multirow{3}{*}{$\begin{array}{c}\text { Dog } \\
\text { wt }\end{array}$} & \multirow{2}{*}{\multicolumn{2}{|c|}{$\mathrm{C}_{\mathrm{IN}}$}} & \multirow{2}{*}{\multicolumn{2}{|c|}{ Nephron GFR }} & \multirow{3}{*}{$\frac{\text { Sup }}{\mathrm{JM}}$} & & & \multicolumn{4}{|c|}{ Zonal plasma flow } & \multicolumn{4}{|c|}{ GPR } \\
\hline & & & & & & & & & \multicolumn{2}{|c|}{ Sup } & \multicolumn{2}{|c|}{$J M$} & \multicolumn{2}{|c|}{ Sup } & \multicolumn{2}{|c|}{$\mathbf{J} \mathbf{M}$} \\
\hline & & Cont & Sal & Sup & $\mathrm{JM}$ & & Cont & Sal & Cont & Sal & Cont & Sal & Cont & Sal & Cont & Sal \\
\hline & $\mathrm{kg}$ & \multicolumn{2}{|c|}{$m l / \min$} & \multicolumn{2}{|c|}{$n l / \min$} & & \multicolumn{2}{|c|}{$m l / \min$} & \multicolumn{4}{|c|}{$\mathrm{ml} / \mathrm{min} / \mathrm{g}$} & \multicolumn{4}{|c|}{$n l / m i n$} \\
\hline 1 & 12.2 & & 43 & $127 \pm 8.3$ & $104 \pm 10.3$ & 1.22 & & 93 & & & & & & & & \\
\hline 2 & 10.0 & 20 & 31 & & & & 46 & 60 & 1.68 & 1.82 & 0.77 & 1.61 & 159 & 173 & 136 & 285 \\
\hline 3 & 9.5 & 23 & 23 & $65 \pm 4.8$ & $62 \pm 8.2$ & 1.05 & 62 & 54 & 2.98 & 2.35 & 0.94 & 2.20 & 283 & 223 & 166 & 389 \\
\hline 4 & 9.5 & 11 & 11 & $66 \pm 8.9$ & $63 \pm 8.1$ & 1.05 & 36 & 53 & 1.98 & 1.96 & 1.11 & 1.60 & 188 & 186 & 196 & 283 \\
\hline 5 & 14.0 & 34 & 24 & $58 \pm 3.2$ & $58 \pm 6.6$ & 1.00 & 108 & 92 & 2.30 & 2.50 & 2.20 & 2.27 & 218 & 237 & 389 & 402 \\
\hline 6 & 13.5 & 32 & 33 & $93 \pm 6.7$ & $97 \pm 5.7$ & 0.96 & 99 & 121 & 3.11 & 3.53 & 1.04 & 1.88 & 295 & 335 & 184 & 333 \\
\hline 7 & 11.5 & 25 & 27 & $72 \pm 4.4$ & $53 \pm 5.5$ & 1.36 & 57 & 94 & 1.60 & 2.48 & 0.72 & 1.45 & 152 & 235 & 127 & 257 \\
\hline 8 & 11.5 & 29 & 28 & & & & 83 & 71 & 1.64 & 1.70 & 1.15 & 1.27 & 156 & 161 & 204 & 225 \\
\hline 9 & 12.7 & 31 & 23 & $52 \pm 3.0$ & $46 \pm 4.7$ & 1.13 & 125 & 76 & 4.01 & 2.83 & 3.00 & 2.29 & 380 & 268 & 531 & 405 \\
\hline 10 & 13.0 & 16 & 16 & $43 \pm 4.6$ & $45 \pm 4.5$ & 0.96 & 43 & 41 & & & & & & & & \\
\hline 11 & 13.2 & 19 & 22 & $64 \pm 4.5$ & $65 \pm 3.7$ & 0.98 & 67 & 58 & 1.40 & 1.63 & 0.53 & 0.54 & 133 & 155 & 94 & 96 \\
\hline 12 & 14.5 & 40 & 39 & $105 \pm 7.8$ & $59 \pm 6.8$ & 1.78 & 83 & 98 & 1.40 & 2.66 & 1.24 & 3.14 & 133 & 252 & 219 & 556 \\
\hline Mean & 12.1 & 26 & 27 & 74 & 65 & 1.15 & 73 & 76 & 2.21 & 2.35 & 1.27 & 1.83 & 210 & 223 & 225 & 323 \\
\hline SEM & 0.5 & 2.6 & 2.6 & 8.2 & 6.2 & 0.08 & 8.6 & 6.8 & 0.28 & 0.19 & 0.24 & 0.22 & 26 & 18 & 42 & 39 \\
\hline
\end{tabular}

Sup, superficial; JM, juxtamedullary ; Cont, control ; Sal, saline loading.

microsphere distribution were not obtained in all dogs of both groups (see Tables I and II).

Tissue preparation for the modified Hanssen technique. While still frozen, the kidney was bisected sagitally and fragmented. The fragments were then transferred to $50 \%$ alcoholic $\mathrm{FeCl}_{3}$ for precipitation of $\mathrm{FeCN}$ as ferroferricyanide (Prussian blue) and prepared for dissection as previously described (12), except that the fragments were kept in $20 \% \mathrm{HCl}$ at $+37^{\circ} \mathrm{C}$

8-14 superficial nephrons (those nephrons having at least one proximal loop on the cortical surface) and 8-14 juxtamedullary nephrons (those from the inner quarter of the cortex having glomeruli as close to the juxtamedullary junction as possible) from 4 randomly selected fragments were dissected, the glomerulus removed, and the tubule divided at the leading edge of the visible Prussian blue granules. The tubule was then transferred to $10 \mathrm{ml}$ of Aquasol (USV Pharmaceutical, Tuckahoe, N. Y.) and counted for $100 \mathrm{~min}$ on a Beckman LS-100 beta scintillation counter (Beckman Instruments, Fullerton, Calif.). In all experiments, sample counts were at least 2.5 times background.

The radioactivity recorded from nephrons prepared as described is derived not only from filtered sodium ferrocyanide (intratubular) but also from sodium ferrocyanide adherent to the outer surface of the tubule or within cells ("contamination"). On the other hand, because the glomerulus was removed, radioactivity within Bowman's space, which represents filtration, was lost. The $\sim$ fore, to calculate radioactivity that represents only filt. tion, subtraction of extratubular contamination, which would otherwise produce an overestimate of filtration, and addition of counts lost from Bowman's space, which would otherwise produce an underestimate of filtration, was necessary. To calculate these corrections, four experiments were performed. Several small lengths of proximal tubule immediately beyond the Prussian blue marker were measured and pooled to approximate the length of the proximal segment used to calculate filtration. These late proximal segments counted $10 \pm 1.8 \%$ (SE) of the experimental samples.
In addition, glomeruli were pooled and counted; counts per glomerulus were $21 \pm 2.7 \%$ of the mean proximal tubular counts. These data were not significantly different for superficial and juxtamedullary nephrons. In correcting for loss of counts from Bowman's space, we assume arbitrarily, as have others $(6,11)$ that $50 \%$ of the glomerular radioactivity represents filtrate. Measured radioactivity in individual experimental nephrons was corrected by the use of these data both for extratubular contamination and for loss of counts in Bowman's space.

Radioactivity was determined separately in each of the 13-16 plasma samples obtained in every experiment by continuous renal artery sampling. The mean plasma radioactivity of all samples in each experiment was used to calculate nephron filtration rates for that experiment.

Tissue preparation for microspheres. A sagittal slice 2-5 $\mathrm{mm}$ thick was cut from the remaining half-kidney and the capsule removed. The slice was further divided into 10 wedges approximately $5 \mathrm{~mm}$ wide by cutting perpendicular to the cortical surface. The cortical width was measured and the wedge placed in the appropriate size block of a series of cutting blocks preset to divide the cortex into four equal zones, parallel to the surface. The pieces were rapidly weighed on a Roller-Smith balance (Roller-Smith, Inc., Newark, N. J.) and placed in gamma counting tubes. Each of the 10 wedges was cut into 4 equal zones in the same manner. The zones were numbered I (superficial) through IV (juxtamedullary). (The flow to zones II and III was measured but has not been presented, since all nephrons used to estimate single nephron filtration rate were from zones I and IV.) The remaining large portion of kidney was weighed and cut into approximately 15 pieces. Radioactivity was determined with a Packard three-channel gamma spectrometer (Packard Instrument Co., Inc., Downers Grove, Ill.). ${ }^{3}$

${ }^{3}$ In several experiments, when the tissue was cut without freezing, there was a significant loss of tissue fluid during cutting and weighing; the smaller zonal pieces lost appreciably more weight than the large pieces. This error would 
Determination of glomerular density. Fragments of tissue from the four zones were pooled separately and placed in $20 \% \mathrm{HCl}$ at $37^{\circ} \mathrm{C}$ for $3 \mathrm{~h}$. The macerated tissue was then diluted to $50 \mathrm{ml}$ with distilled water and $3 \mathrm{ml}$ of $10 \%$ lissamine green, added to facilitate detection of glomeruli. After vigorous shaking, the suspension was continuously mixed. Six 1-ml samples, taken from separate areas of the flask, were transferred to a counting chamber and all the glomeruli in each sample were counted.

Inulin, PAH, sodium, and plasma proteins were determined as previously described (13). Student's $t$ test was used to determine statistical significance of most data. However, determination of the significance of differences in the ratios SNGFR: JMGFR has been analyzed by the fourfold median test (14), which is more appropriate for this type of comparison. All values are given as means \pm SEM.

Calculations.

$$
\text { Single nephron GFR }=\frac{\text { tubular cpm }}{\begin{array}{c}
\text { Plasma cpm/lambda } \times 10^{3} \times \text { time of } \\
\text { infusion of radioactivity }(\mathrm{min})
\end{array}}
$$

Tissue plasma flow $(f)(\mathrm{ml} / \mathrm{min} / \mathrm{g}) f=\frac{q}{Q_{w}} \times R P F$,

where $q=$ radioactivity of a tissue slice of weight $w ; Q$ $=$ the total radioactivity of the kidney; and $R P F=$ the renal plasma flow calculated from the clearance of PAH."

$$
\begin{aligned}
& \text { Glomerular density }=\text { number of glomeruli } / g \text {, } \\
& \text { and } \\
& \text { Glomerular perfusion rate }(\mathrm{GPR})=\frac{f}{\text { number of glomeruli } / \mathrm{g}}
\end{aligned}
$$

\section{RESULTS}

Since measurement of single nephron filtration rate by the Hanssen technique can only be done once in each dog, it is important that experimental groups have comparable control measurements (Tables I and II). The control dogs (group I) and the dogs in which control and saline-loading measurements were made (group II) were comparable in body weight: 13.6 vs. $12.1 \mathrm{~kg}$, respectively. In addition, during control measurements clearance of inulin ( $\mathrm{C}_{\mathrm{IN}}$ ), $29 \pm 2$ vs. $26 \pm 3 \mathrm{ml} / \mathrm{min}$, and clearance of $\mathrm{PAH}$ ( $\mathrm{C}_{\mathrm{PAB}}$ ), $85 \pm 17$ vs. $73 \pm 9 \mathrm{ml} / \mathrm{min}$, were not statistically different. Systemic blood pressure, serum proteins, and hematocrit, not shown in the tables, were also comparable in the two groups.

lead to overestimates of zonal flow. In addition, the tissue from the saline-loaded animals lost approximately $15 \%$ more weight than the tissue from the control animals. This would result in discrepancies in calculation of flow/g in the two groups. These potential errors were avoided by cutting and weighing the kidneys while frozen.

4 The radioactivity of each tissue slice was counted separately; the value for $q$ used to calculate flow to each zone was the mean of the 10 small pieces cut from that zone. $Q$ was calculated as equal to total radioactivity of the 15 pieces cut from the large portion of kidney, multiplied by (total kidney wt/wt of large portion). $R P F$ was calculated from $\mathrm{C}_{\mathrm{PAH}}$, with values for $\mathrm{PAH}$ extraction obtained from comparable experiments in our laboratory (15).

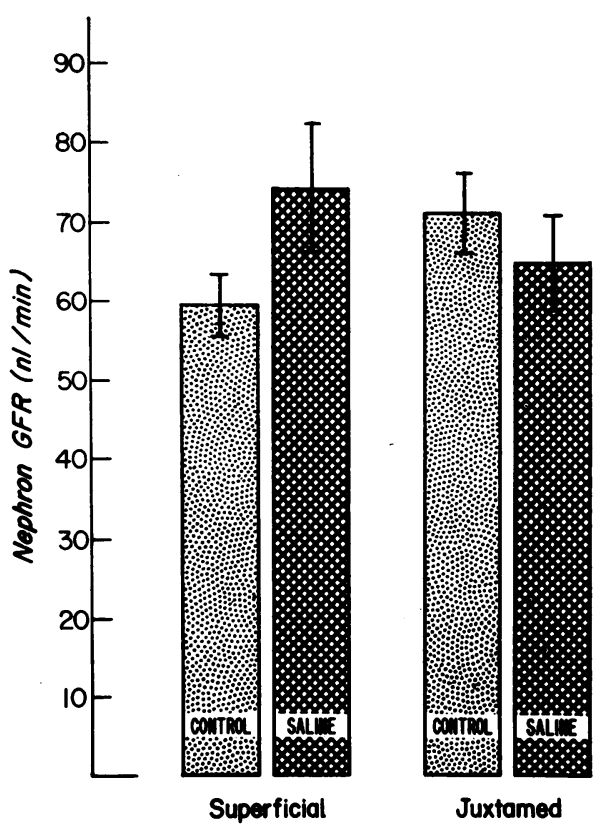

Figure 1 The effect of saline loading on SNGFR and JMGFR.

SNGFR and JMGFR during control and saline loading. In group I control SNGFR, $60 \pm 4 \mathrm{nl} / \mathrm{min}$, was different from JMGFR, $72 \pm 5 \mathrm{nl} / \mathrm{min}(P<0.01)$. In group II $C_{\text {IN }}$ did not change significantly during saline loading. Sodium excretion increased to $169 \pm 43 \mu \mathrm{eq} / \mathrm{min} /$ kidney. Nephron GFR was measured in 10 of these 12 dogs after volume expansion. SNGFR was $74 \pm 8 \mathrm{nl} / \mathrm{min}$ and JMGFR was $65 \pm 6 \mathrm{nl} / \mathrm{min}$ (Tables I and II, Fig. 1). While SNGFR was larger during saline loading, this difference was not statistically different. Similarly, JMGFR was lower during saline loading, but not statistically different. However, the ratio SNGFR: JMGFR during control was $0.84 \pm 0.03$ and during saline loading was $1.15 \pm 0.08(P<0.001)$. In addition, the ratio SNGFR: $C_{\text {IN }}$ was $2.1 \pm 0.24 \times 10^{8}$ during control and $3.0 \pm 0.31 \times 10^{8}$ during saline loading $(P<0.05)$. The ratio JMGFR: $\mathrm{C}_{1 \mathrm{~N}}$ was not different when control and saline-loading values were compared.

Intrarenal plasma flow during hydropenia and saline loading. Results are summarized in Tables I and II. Intrarenal plasma flow distribution was determined in $6 \mathrm{dogs}$ from group I during control and in $10 \mathrm{dogs}$ from group II during both control and saline loading. In the control state, plasma flow was comparable in the two groups of dogs, both in the superficial and in the juxtamedullary zones. During saline loading $\mathrm{C}_{\mathbf{P A}}$ did not change significantly in group II, nor did superficial cortical flow. In the juxtamedullary zone, however, flow increased markedly from 1.3 to $1.8 \mathrm{ml} / \mathrm{min} / \mathrm{g}(P<$ 0.01 ). 
TABLE III

Calculation of Predicted Kidney GFR from Observed Nephron GFR Values in Hydropenic Dogs

\begin{tabular}{|c|c|c|c|c|}
\hline Zone & Glomeruli/g & $\begin{array}{c}\text { Glomeruli/ } \\
\text { zone* }\end{array}$ & $\begin{array}{c}\text { Nephron } \\
\text { GFR }\end{array}$ & $\begin{array}{l}\text { Predicted } \\
\quad \mathrm{C}_{\text {IN }}\end{array}$ \\
\hline & $g^{-1}$ & & $n l / \min$ & $m l / \min$ \\
\hline I & $10,547 \pm 1,215$ & 158,205 & 60.0 & 9.5 \\
\hline II & $11,316 \pm 546$ & 138,055 & $(63.9)$ & 8.8 \\
\hline III & $9,993 \pm 712$ & 93,934 & $(67.8)$ & 6.4 \\
\hline IV & $5,650 \pm 1,275 \S$ & 37,855 & 71.6 & 2.7 \\
\hline \multicolumn{3}{|c|}{ tal $C_{\text {IN }}$ predicted } & & $\begin{array}{l}27.4 \\
20\end{array}$ \\
\hline
\end{tabular}

* Glomeruli/g $\times$ mean kidney weight $(g) \times$ fraction of kidney weight in zone, as estimated by the approximation of McNay and Abe (33). This assumes that the zones are concentric ellipsoids and gives estimates of $0.27,0.22,0.17$, and $0.12 \%$ for the weights of zones I through IV as fractions of whole kidney weight.

$\ddagger$ Nephron filtration rates for zones I and IV are the measured values for SNGFR and JMGFR (Table I). Values for zones II and III are interpolated on the assumption that nephron GFR increases as a continuous function from I to IV.

$\$$ Low value may reflect, in part, inclusion of outer medulla in this zone.

GPR was calculated from the mean glomerular density measurement obtained from 23 kidneys (Table III). Individual experimental data for GPR in the superficial and juxtamedullary zones are recorded in Tables I and II. GPR did not change significantly during saline loading in the superficial zone, but in the juxtamedullary zone, GPR increased from $225 \pm 42 \mathrm{nl} / \mathrm{min}$ in hydropenia to $323 \pm 39 \mathrm{nl} / \mathrm{min}$ during volume expansion $(P<0.01)$ (Fig. 2).

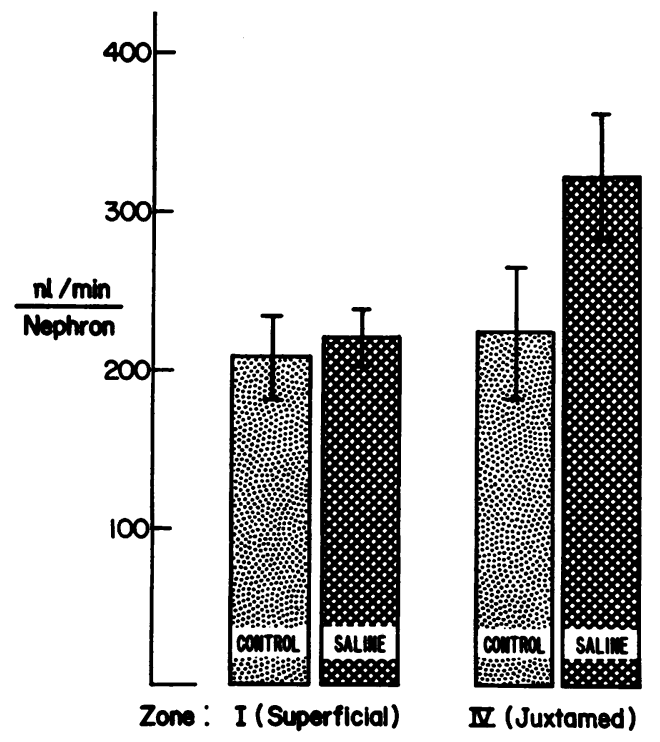

Figure 2 The effect of saline loading on superficial and juxtamedullary nephron plasma flow.

\section{DISCUSSION}

The principal new finding in these studies is that there is a redistribution of nephron filtration during saline loading in the dog. This conclusion is based on a variant of the Hanssen method $(9,10)$ as modified by others (6-8). Several sources of error are recognized as possible hazards in using this method for quantitative estimation of individual nephron GFR. First, there is evidence that some of the radioactivity in the dissected nephrons is extraluminal and does not represent $\mathrm{FeCN}$ delivered by filtration. In experiments designed to evaluate this possible cause of overestimation of nephron GFR, we measured the radioactivity of pooled short segments from proximal tubules at a site just beyond the marker of precipitated Prussian blue. Radioactivity per unit length in these segments was about $10 \%$ of that in the adjacent test segments of superficial and juxtamedullary tubules proximal to the filtration marker. There was relatively little variation in this figure in the four experiments performed: $7,12,8$, and $13 \%$. However, even rather large fractional changes in this value would influence estimates of nephron GFR relatively little, since the contamination is only $10 \%$ of the radioactivity due to true filtration. A similar value for extraluminal radioactivity was obtained by Carriere et al. (4), using a different modification of the Hanssen method in the dog. Roughly comparable estimates of contamination in the rat were made by Baines and de Rouffignac (16, 17) and Coelho, Chien, Stella, and Bradley (18); Bonvalet, Bencsath, and de Rouffignac (6) found negligible amounts, however.

Second, we removed the glomeruli, which contained some radioactivity in Bowman's space that represents filtration. In several experiments, radioactivity in superficial and deep glomeruli was about $20 \%$ of radioactivity in tubules from the same kidneys. This was slightly higher than that found by Baines in the rat (17). There was relatively little variation among the four experiments: $24,13,24$, and $24 \%$. We assumed arbitrarily, as have others $(6,11)$, that half of glomerular radioactivity is in Bowman's space and corrected measured tubular counts for loss of filtrate in glomeruli accordingly. Since the correction was only about $10 \%$ of the value for tubular radioactivity, even relatively large fractional changes in this correction would have little effect on absolute values of nephron GFR.

Third, there are possible errors attributable to our variant of the de Rouffignac-Hanssen method, in which the $\mathrm{FeCN}$ was infused into the aorta near the renal 
artery rather than intravenously. (This modification was required because of the prohibitive cost of the amount of radioactive $\mathrm{FeCN}$ necessary to achieve adequate plasma levels of radioactivity by systemic infusion.) Homogeneous distribution of the $\mathrm{FeCN}$ was confirmed by routinely dissecting multiple pieces from random areas of the kidney and finding Prussian blue granules in virtually all nephrons dissected. An adequate estimate of renal plasma radioactivity was obtained by sampling blood in the renal artery at 1 -s intervals throughout the infusion of radioactivity. This provided 13-16 separate plasma samples, from which mean plasma radioactivity could be estimated reasonably accurately.

These factors obviously introduce some uncertainty in calculations of absolute values of nephron GFR. However, any errors should apply equally to superficial and juxtamedullary nephrons and should not affect the ratio SNGFR: JMGFR. This ratio in control dogs in our present study is quite similar to those found in the rat $(6,7,18)$ and the dog (4) by others.

Moreover, it is unlikely that even the absolute values are seriously in error. The present values for SNGFR in control dogs are comparable to those obtained by micropuncture $(1-3,19,20)$. SNGFR in control dogs was estimated as $64 \pm 3$ by micropuncture in our laboratory (1) and was $60 \pm 4$ by the Hanssen method in the present study. Mean kidney GFR was $29 \mathrm{ml} / \mathrm{min}$ in each group of dogs. Further evidence that our modified method gives reasonable absolute values is provided by comparison of observed whole kidney GFR with that predicted from nephron GFR measurements and glomerular counts. ${ }^{5}$ The calculation for the hydropenic dogs is detailed in Table III. The calculated value of 27.4 $\mathrm{ml} / \mathrm{min}$ is in excellent agreement with the observed value of 29 (Table I). Similar calculations for the saline-loaded dogs in Table II gave a predicted value of 30.6 , in good agreement with the observed value of 27 . We recognize the need for caution against interpreting too exactly quantitative estimates derived from a method that requires a number of corrections Nevertheless, the considerations in this paragraph support the view that useful estimates of SNGFR and JMGFR in the dog can be obtained with our modified Hanssen technique.

Our data clearly demonstrate a shift in intrarenal distribution of filtrate during acute saline loading. The SNGFR: JMGFR ratio of 1.15 during saline loading is significantly different from 0.84 during the control state. This redistribution of filtrate appeared to involve

\footnotetext{
${ }^{5}$ The number of glomeruli/g of whole kidney (not divided into zones) was 8,200. This is in excellent agreement with recent data of Schneider, Lynch, Willis, and Knox (3), who found 8,100 glomeruli/g of kidney.
}

both an increase in superficial and a reduction in JMGFR although neither change, by itself, was significant. In dog micropuncture experiments, redistribution of filtrate with saline loading has been estimated by comparing superficial to whole-kidney filtration rate. Because of appreciation of and correction for the "repuncture artifact" $(1,2)$, measurement of this ratio has not suggested redistribution in the $\operatorname{dog}(1-3)$. In the present experiments, the ratio of superficial to wholekidney GFR increased after saline loading, although the difference barely achieves statistical significance $(P<$ $0.05)$. Direct measurement of both superficial and deep filtration rate by microdissection should, in principle, be more accurate than micropuncture methods for assessing distributional changes in the dog. Juxtamedullary nephrons, as defined and calculated by our methods of dissection, are only about $5-15 \%$ of the total in the kidney. Fairly large changes in JMGFR could be missed when GFR in this small fraction of nephrons is estimated indirectly by comparing SNGFR from micropuncture with kidney GFR. Unfortunately, there are conflicting data even with the use of the more direct Hanssen method. Carriere et al. (4) have recently published data from experiments quite similar to ours utilizing the Hanssen technique in dogs, but with measurement only of the SNGFR: JMGFR ratio. During hydropenia the ratio in their studies was 0.80 , not different from the value obtained in our experiments. After saline loading, however, they found no change in the ratio in five dogs. We have no definite explanation for the discrepancy. However, we do have an additional check on the validity of our technique not available with their qualitative method, in the agreement between our absolute nephron GFR values with micropuncture values and with kidney GFR (Table III). As Carriere et al. (4) point out, the difference between our results may be related to the slightly larger saline load infused in our studies. In small rats in which direct micropuncture measurements of JMGFR can be made, superficial redistribution has been found after volume expansion $(21,22)$. In larger rats, estimates of distribution derived from the ratio of SNGFR to wholekidney GFR have been inconclusive $(23,24)$ or negative $(25,26)$ with respect to superficial shifts during volume expansion. Baines (17) has recently found that redistribution occurs in small but not larger rats (Hanssen method) and suggested that structural changes with age may modify this response. Whatever the explanation, data both in rats and in dogs are still in conflict as to whether SNGFR increases out of proportion to JMGFR or whole-kidney GFR with saline infusion.

In our experiments, there was a striking increase in juxtamedullary blood flow after saline expansion, 
while perfusion did not change in the superficial cortex." Similar results have been reported by other laboratories $(27-29)$. The accuracy of the changes in intrarenal blood flow distribution which we have recorded is, of course, entirely dependent upon the validity of the microsphere technique. Wallin, Rector, and Seldin, and Katz, Blantz, Rector, and Seldin $(29,30)$ have suggested that superficial streaming of microspheres occurs during hydropenia, which artifactually elevates measured blood flow to the superficial cortex. During saline loading this artifact is reduced because of decreased blood viscosity, leading to an apparent shift of blood flow to the juxtamedullary area. To the extent that the distribution of microspheres mimics the distribution of red blood cells, this seems unlikely. Calculations of superficial nephron filtration fraction from hematocrit and from protein concentration in efferent arterioles give equal values $(31,32)$. Were significant red cell skimming present, higher values should have been obtained with the hematocrit method. Similar results have been reported with volume-expanded rats (26). It is possible, however, that microspheres, which are $15 \mu \mathrm{m}$, might be skimmed while the smaller red cells are not. The evidence for this is inconclusive. Katz (30) et al. found evidence that larger spheres distributed preferentially to superficial areas in comparison to $15 \mu \mathrm{m}$ spheres, while McNay and Abe (33) did not. The most telling evidence in favor of a streaming artifact is the discrepancy between microsphere and antiglomerular basement membrane antibody techniques reported by Wallin et al (29). With the latter method, they found no significant redistribution in blood flow after saline infusion equal to $8 \%$ of body wt $/ \mathrm{h}$. With microspheres, both rates of infusion induced a large shift to the juxtamedullary area, comparable to that found in the present study. These workers suggested that the antibody measures true changes in plasma flow, whereas the microspheres overestimate the deep shift in flow because of the streaming artifact discussed above. This evidence, although striking, must be considered inconclusive at present, since other investigators have raised serious questions about the validity of the antibody technique (34). It should be noted, in any case, that both the microsphere and the antibody technique demonstrate that increased blood flow to juxtamedullary glomeruli occurs during saline

\footnotetext{
- Absolute zonal perfusion rates depend on whole-kidney plasma flow, estimated as $\mathrm{C}_{\mathrm{PAB}} / 0.8$. This value was obtained in previous work in this laboratory (15), in which it was found that saline infused as in the present study does not alter PAH extraction. Any difference between 0.8 and the actual extraction in the present study might alter absolute perfusion rates slightly, but would not, of course, alter the differences between zones I and IV. Any tendency for $\mathrm{PAH}$ extraction to fall during saline infusion would magnify the absolute increment in flow in each zone, but the relative changes would not be affected.
}

loading, although the magnitude of the change is in dispute.

The physiological significance of this redistribution of intrarenal blood flow and its relation to sodium excretion is conjectural. It is unlikely that increases in deep blood flow alone account for enhanced sodium excretion, since similar distributional changes have been found in nonnatriuretic states as well $(33,35)$. Stein, Boonjarern, Mauk, and Ferris have suggested (36) that redistribution to the inner zone may be a function of renal vasodilatation per se and is not directly related to volume expansion or to changes in sodium excretion. Both GPR and nephron GFR were measured in the same dog in most of our experiments. From these data, nephron filtration fraction was calculated and the results are recorded in Table IV. The nephrons in which

TABLE IV

Kidney and Nephron Filtration Fraction

\begin{tabular}{lcc}
\hline & Group I & Group II \\
\hline & $(n=5)$ & $(n=8)$ \\
Kidney FF & $0.37 \pm 0.05$ & $0.32 \pm 0.03$ \\
Superficial nephron & & \\
GFR, $n l /$ min & $61 \pm 7.1$ & $72 \pm 6.4$ \\
GPR, $n l /$ min & $207 \pm 23$ & $236 \pm 19$ \\
FF & $0.31 \pm 0.04$ & $0.31 \pm 0.03$ \\
Juxtamedullary nephron & & \\
GFR, $n l /$ min & $76 \pm 6.6$ & $63 \pm 5.3$ \\
GPR, $n l /$ min & $271 \pm 66$ & $340 \pm 48$ \\
FF & $0.34 \pm 0.07$ & $0.24 \pm 0.07$ \\
\hline
\end{tabular}

$\mathrm{FF}$, filtration fraction.

GFR was measured were dissected from the same superficial and juxtamedullary areas of the kidney used to measure GPR. Since nephron filtration fraction must be derived from two sets of observations and each has a considerable number of potential errors, we recognize the quantitative limitation of these calculated nephron filtration fractions. The results are instructive nonetheless. Superficial filtration fraction was 0.31 during hydropenia and was not different during saline loading. This is in agreement with the results of Daugharty, Ueki, Nicholas, and Brenner (26), who calculated superficial filtration fraction from protein concentration and hematocrit of the superficial peritubular capillaries in the rat. Filtration fraction in the juxtamedullary nephrons was 0.34 in the hydropenic animals and 0.24 during saline expansion. This apparent decrement in juxtamedullary filtration fraction is in agreement with the results obtained by Nissen (37) in the cat, in which venous blood draining the deep cortex can be sampled directly. It also fits the predictions of others from micropuncture and intrarenal blood flow studies $(38,28)$. It is tempting to speculate that this apparent reduction in 
juxtamedullary nephron filtration fraction plays a role in effecting the natriuresis that occurs. The reduction in filtration fraction in juxtamedullary nephrons presumably indicates that during saline loading oncotic pressure in peritubular capillaries surrounding these nephrons is reduced more than in superficial nephrons. Since decreased oncotic pressure is a major determinant of decreased sodium reabsorption in the proximal tubule $(26,31)$, it may be that proximal reabsorption is reduced more in juxtamedullary than in superficial nephrons during saline loading. Moreover, medullary blood flow is derived from the post-glomerular circulation of juxtamedullary nephrons. Hence, the increase in plasma flow and presumed large decrease in peritubular oncotic pressure in the deep cortical zone suggest that similar changes may occur in the medullary circulation. Such circulatory changes could be a factor in determining alterations in sodium reabsorption in the loops of Henle in response to saline loading (39). It must be emphasized, however, that there is no specific evidence in our data that favors a relation between natriuresis and the hemodynamic changes we observed.

In recent work, Brenner, Troy, Daugharty, Deen, and Robertson (40-42) have shown that filtration rate in superficial nephrons is strikingly plasma-dependent. Our data in superficial nephrons is in agreement with this concept, since filtration fraction was unchanged after volume expansion. Our findings in juxtamedullary nephrons are apparently contradictory, however, since JMGFR tended to fall, while plasma flow increased about $50 \%$. However, juxtamedullary glomeruli and efferent arterioles are larger than the corresponding structures of superficial nephrons $(3,43)$. It has also been noted that renin content per glomerulus decreases progressively from the superficial to the deep zones of the cortex (44). Hence, as Daugharty et al. have also noted (26), the relation between GFR and plasma flow may differ in juxtamedullary and superficial nephrons, because of differences in such factors as afferent and efferent arteriolar resistance, net filtration pressure, the glomerular capillary oncotic pressure profile, and capillary permeability. Such differences may account for the apparent lack of plasma-flow-dependence of GFR in juxtamedullary nephrons observed in the present study.

\section{ACKNOWLEDGMENTS}

We are indebted to Prof. Arthur Albert, Dept. of Mathematics, Boston University, for his help in the statistical evaluation utilized.

The authors greatly appreciate the technical assistance of Jack Wawrzynski and Eileen McNamara.

These studies were supported by National Institutes of Health grants AO 3-14004-3, AM 11733, and AM 05209.

\section{REFER ENCES}

1. Auld, R. B., E. A. Alexander, and N. G. Levinsky.
1971. Proximal tubular function in dogs with thoracic caval constriction. J. Clin. Invest. 50: 2150.

2. Mandin, H., A. H. Israelit, F. C. Rector, and D. W. Seldin. 1971. Effect of saline infusions on intrarenal distribution of glomerular filtrate and proximal reabsorption in the dog. J. Clin. Invest. 50: 514.

3. Schneider, E. G., R. E. Lynch, L. R. Willis, and F. G. Knox. 1972. Single-nephron filtration rate in the dog. Am. J. Physiol. 222: 667.

4. Carriere, S., P. Boulet, A. Mathieu, and M. G. Brunette. 1972. Isotonic saline loading and intrarenal distribution of glomerular filtration in dogs. Kidney Int. 2: 191.

5. Bruns, F. J., A. L. Riley, E. A. Alexander, and N. G. Levinsky. 1972. The quantitative estimation of juxtamedullary and superficial nephron filtration in the dog: control and saline loading. Clin. Res. 20: 588.

6. Bonvalet, J. P., P. Bencsath, and C. de Rouffignac. 1972. Glomerular filtration rate of superficial and deep nephrons during aortic constriction. Am. J. Physiol. 222: 599.

7. Rouffignac, C. de, S. Deiss, and J. P. Bonvalet. 1970. Determination du taux individuel de filtration glomèrulaire des nephrons accessibles et inaccessibles à la microponction. Pfiugers Arch. Eur. J. Physiol. 315: 273.

8. Coelho, J. B., K. C. H. Chien, and S. E. Bradley. 1972. Measurement of single-nephron glomerular filtration rate without micropuncture. Am. J. Physiol. 223: 832.

9. Hanssen, O. E. 1958. Histochemical method for the evaluation of excreted sodium ferrocyanide in isolated tubules of the mouse kidney. Acta Pathol. Microbiol. Scand. $44: 363$.

10. Hanssen, O. E. 1963. Method for comparison of glomerular filtration in individual rat nephrons. Proc. Int. Congr. Nephrol. 2: 527.

11. Rouffignac, C. de, and J. P. Bonvalet. 1972. Use of sodium ferrocyanide as glomerular indicator to study the functional heterogeneity of nephrons. Yale J. Biol. Med. $45: 243$.

12. Morris, C. R., E. A. Alexander, F. J. Bruns, and N. G. Levinsky. 1972. Restoration and maintenance of glomerular filtration by mannitol during hypoperfusion of the kidney. J. Clin. Invest. 51: 1555.

13. Levinsky, N. G., and R. C. Lalone. 1963. The mechanism of sodium diuresis following saline infusion in the dog. J. Clin. Invest. 42: 1261.

14. Mood, A. M., and F. A. Graybill. 1963. Introduction to the Theory of Statistics. McGraw-Hill Book Company, New York. 2nd edition. 412.

15. Shuster, A., E. A. Alexander, R. C. Lalone, and N. G. Levinsky. 1966. Renal blood flow, sodium excretion, and concentrating ability during saline infusion. Am. J. Physiol. 211: 1181.

16. Baines, A. D., and C. de Rouffignac. 1969. Functional heterogeneity of nephrons. II. Filtration rates, intraluminal flow velocities, and fractional water reabsorption. Pfiügers Arch. Eur. J. Physiol. 308: 260.

17. Baines, A. D. 1973. Redistribution of nephron function in response to chronic and acute solute loads. Am. J. Physiol. 224 : 237.

18. Coelho, J. B., K. C. H. Chien, S. R. Stella, and S. E. Bradley. 1971. Relationship of extraluminal tubular deposition of ferrocyanide to peritubular perfusion rate in cortical and medullary nephron segments of the rat kidney. Circ. Res. 29: 21. 
19. Knox, F. G., E. G. Schneider, T. P. Dresser, and R. E. Lynch. 1970. Natriuretic effect of increased proximal delivery in dogs with salt retention. Am. J. Physiol. 219: 904 .

20. Wright, F. S., S. S. Howards, F. G. Knox, and R. W. Berliner. 1969. Measurement of sodium reabsorption by proximal tubule of the dog. Am. J. Physiol. 217: 199.

21. Horster, M., B. J. Kemler, and H. Valtin. 1971. Intracortical distribution of number and volume of glomeruli during postnatal maturation in the dog. $J$. Clin. Invest. 50: 796.

22. Jamison, R. L., and F. R. Lacy. 1971. Effect of saline infusion on superficial and juxtamedullary nephrons in the rat. Am. J. Physiol. 221: 690.

23. Davidman, M., E. A. Alexander, R. Lalone, and N. G. Levinsky. 1972. Nephron function during volume expansion in the rat. Am. J. Physiol. 223: 188.

24. Herrera-Acosta, J., V. E. Andreucci, F. C. Rector, and D. W. Seldin. 1972. Effect of expansion of extracellular volume on single-nephron filtration rates in the rat. Am. J. Physiol. 222 : 938.

25. Bartoli, E., and L. E. Earley. 1971. The relative contributions of reabsorptive rate and redistributed nephron filtration rate to changes in proximal tubular fractional reabsorption during acute saline infusion and aortic constriction in the rat. J. Clin. Invest. 50: 2191.

26. Daugharty, T. M., I. F. Ueki, D. P. Nicholas, and B. M. Brenner. 1972. Comparative renal effects of isoncotic and colloid-free volume expansion in the rat. Am. J. Physiol. 222 : 225.

27. Blantz, R. C., M. A. Katz, F. C. Rector, Jr., and D. W. Seldin. 1971. Measurement of intrarenal blood flow. II. Effect of saline diuresis in the dog. Am. J. Physiol. 220: 1914

28. Stein, J. H., R. W. Osgood, and T. F. Ferris. 1972. Effect of volume expansion of distribution of glomerular filtrate and renal cortical blood flow in the dog. Am. J. Physiol. 223 : 984.

29. Wallin, J. D., F. C. Rector, Jr., and D. W. Seldin. 1972. Effect of volume expansion on intrarenal distribution of plasma flow in the dog. Am. J. Physiol. 223: 125.

30. Katz, M. A., R. C. Blantz, F. C. Rector, Jr., and D. W. Seldin. 1971. Measurement of intrarenal blood flow. I. Analysis of microsphere method. Am. J. Physiol. 220 : 1903.

31. Brenner, B. M., and J. L. Troy. 1971. Postglomerular vascular protein concentration: evidence for a causal role in governing fluid reabsorption and glomerulotubular balance by the renal proximal tubule. J. Clin. Invest. $50: 336$.

32. Stein, J. H., R. C. Congbalay, D. L. Karsh, R. W. Osgood, and T. F. Ferris. 1972. The effect of bradykinin on proximal tubular sodium reabsorption in the dog: evidence for functional nephron heterogeneity. J. Clin. Invest. 51 : 1709.

33. McNay, J. L., and Y. Abe. 1970. Pressure dependent heterogeneity of renal cortical blood flow in dogs. Circ. Res. $27: 571$

34. Stein, J. H., S. Boonjarern, C. B. Wilson, and T. F. Ferris. 1973. Alterations in intrarenal blood flow distribution. Circ. Res. 32, 33: 1-61.

35. Bay, W. H., J. H. Stein, J. B. Rector, R. W. Osgood, and T. F. Ferris, 1972. Redistribution of renal cortical blood flow during elevated ureteral pressure in the dog. Am. J. Physiol. 222: 33.

36. Stein, J. H., S. Boonjarern, R. C. Mauk, and T. F. Ferris. 1973. Mechanism of the redistribution of renal cortical blood flow during hemorrhagic hypotension in the dog. J. Clin. Invest. 52: 39.

37. Nissen, O. I. 1968. Changes in the filtration fractions in the superficial and deep venous drainage area of the cat kidney due to fluid loading. Acta Physiol. Scand. 68: 1 .

38. Barratt, L. J., J. D. Wallin, F. C. Rector, Jr., and D. W. Seldin. 1973. Influence of volume expansion on single-nephron filtration rate and plasma flow in the rat. Am. J. Physiol. $224: 643$.

39. Earley, L. E., and R. M. Friedler. 1965. Changes in renal blood flow and possibly the intrarenal distribution of blood during the natriuresis accompanying saline loading in the dog. J. Clin. Invest. 44: 929.

40. Brenner, B. M., J. L. Troy, T. M. Daugharty, W. M. Deen, and C. R. Robertson. 1972. Dynamics of glomerular ultrafiltration in the rat. II. Plasma-flow dependence of GFR. Am. J. Physiol. 223: 1184.

41. Deen, W. M., C. R. Robertson, and B. M. Brenner. 1972. A model of glomerular ultrafiltration in the rat. Am. J. Physiol. 223: 1178.

42. Robertson, C. R., W. M. Deen, J. L. Troy, and B. M. Brenner. 1972. Dynamics of glomerular ultrafiltration in the rat. III. Hemodynamics and autoregulation. $\mathrm{Am}$. J. Physiol. 223: 1191.

43. Moffat, D. B., and J. Fourman. 1963. The vascular pattern of the rat kidney. J. Anat. 97: 543.

44. Granger, P., H. Dahlheim, and K. Thurau. 1972. Enzyme activities of the single juxtaglomerular apparatus in the rat kidney. Kidney Int. 1: 78. 